47. Christian Science Monitor. 1926. October 28.

48. Hartford Courant. 1926. October 8.

49. The Scotsman. 1926. November 10.

50. Yorkshire Post and Leeds Intelligencer. 1926.

November 25.

51. Ball A. Imagining America: Influence and Imag-

es in Twentieth-Century Russia. New York, 2004.

52. Christian Science Monitor. 1926. December 7.

53. Los Angeles Times. 1927. May 24.

54. Boston Daily Globe. 1927. November 2.

55. Boston Daily Globe. 1928. August 1.

56. Aberdeen Press and Journal. 1928. July 10.
57. Chicago Daily Tribune. 1928. December 27.

58. Chicago Daily Tribune. 1929. April 14.

59. Rassweiler A. The Generation of Power: The History of Dneprostroi. Oxford, 1988.

60. Hughes T. American Genesis: A Century of Invention and Technological Enthusiasm, 1870-1970. Chicago, 2004.

61. Mumford L. Technics and Civilization. Chicago, 2010.

Исследование выполнено по заказу «Т Плюс Самара».

\title{
RUSSIA ELECTRIFICATION PLAN IN THE USA AND UK PRESS ASSESSMENT OF THE 1920-1929
} (C) 2018

Buranok Sergey Olegovich, doctor of historical sciences, professor of World History, Law and Methods of Teaching Department Samara State University of Social Sciences and Education (Samara, Russian Federation)

Abstract. The following paper deals with the research of the place and value of Russia electrification plan and its reflection in Great Britain and the USA public opinion. The study of information campaign around Russia electrification plan has its specifics and value: first, it gives a chance to establish new, unknown facts; secondly, to determine the level of knowledge of «Another» (in this case, American) society about the Soviet power; thirdly, to understand what place information about Russia electrification plan took in the USA and Great Britain in the system of the USSR image creation, the image of «the Soviet power revolution». This paper uses materials of the USA and Great Britain press about Russia electrification plan. Besides, the author analyzes the image of the Soviet power in the American and British society. The information campaign around Russia electrification plan could report to the world about the Soviet economy achievements as well as promote preparation (in the information plan) to the following large project - industrialization. Articles, reports, notes on Russia electrification plan helped to change the attitude towards Russia / the USSR in the USA and Great Britain and helped to correct the image of the USSR in the world.

Keywords: electrification; USSR economy; Russia electrification plan; periodicals of USA; power supply systems of USSR; Soviet heavy industry; periodicals of Great Britain; H. Wells; V.I. Lenin; public opinion; Dneproges; economic development of USSR; industrialization.

УДК 94

Статья поступила в редакцию 26.01.2017

\section{ОРГАНИЗАЦИОННАЯ СТРУКТУРА МИССИИ ШВЕДСКОГО КРАСНОГО КРЕСТА ПО ОКАЗАНИЮ ПОМОЩИ ГОЛОДАЮЩИМ САМАРСКОЙ ГУБЕРНИИ ВО ВРЕМЯ ГОЛОДА 1921-1923 ГОДОВ}

(C) 2018

Циденков Григорий Геннадиевич, кандидат социологических наук, доцент кафедры управления и сервиса Самарский государственный сочиально-педагогический университет (2. Самара, Российская Федераиия)

Аннотация. В период с декабря 1921 г. по август 1923 г. В Самарской губернии осуществляла гуманитарную деятельность экспедиция Шведского Красного Креста. В статье рассматриваются структура управления экспедицией, форма ее организации. Представлены кадровый состав и принципы, по которым строилось управление экспедиции. Участники экспедиции персонифицируются с указанием их должностей и круга обязанностей. Указываются причины нарастающего увеличения штата экспедиции. Основной массив данных, представленных в статье, получен в результате трехмесячной исследовательской работы в Национальном архиве Швеции (Riksarkivet) и впервые вводится в научный оборот. В статье приводится оценка, данная организации и эффективности работы Шведского Креста представителями советской власти в Самаре. Указаны все основные административные районы Самарской губернии, в которых осуществлялась непосредственная работа сотрудников Шведского Красного Креста. Представленные в статье материалы расширяют наше представление о деятельности иностранных гуманитарных миссий в Поволжье в 1921-1923 годах и могут использоваться для анализа эффективности деятельности экспедиции Шведского Красного Креста в Самарской губернии в указанный период.

Ключевые слова: голод 1921-1923 годов; иностранная помощь; Шведский Красный Крест; экспедиция Шведского Красного Креста; Международный комитет помощи России; Самарская губерния; управление; организационная структура; распределение продовольствия; производственная помощь.

Основным доступным источником информации, освещающей деятельность Шведского Красного Креста (далее - ШКК) в Поволжье во время голода 1921-1923 годов, в настоящее время является совместный сборник документов ГБУСО «Самарский областной государственный архив социально-политической истории» и ГБУСО «Центральный государственный архив Самарской области» «Голод в Средневолжском Крае в 20-30-е годы XX века. Том 1. Голод в Самарской губернии в 20-е годы XX века» [1]. 
Важным источником документальных сведений о работе иностранных миссий помощи на территории Самарской губернии является сборник Самарской губернской комиссии помощи голодающим «На фронте голода» [2]. В то же время следует отметить, что до настоящего времени шведские источники по данной проблематике в научный оборот не вводились. Причиной тому можно указать отсутствие исследований отечественных ученых в шведских архивах и отсутствие научных исследований по данной тематике в самой Швеции. Публикации шведских газет того времени, освещающие деятельность экспедиции, а также разрозненные записки доктора Вассена (участника экспедиции) на русский язык никогда не переводились и в свободном доступе отсутствуют. В статье автор использует материалы из фондов ШКК (Svenska Röda Korset, SKR) Национального архива Швеции. В ссылках указываются фонд и номер дела без указания номера листа, так как листы не сшиты и не пронумерованы. Еще одним источником информации являются публикации в советских газетах 1920-х годов, особенно в самарской «Коммуне». Кроме того, эта проблема раскрыта в научных публикациях, обобщающих сведения отечественных архивов о работе шведской экспедиции. В качестве примера можно привести статьи Ю.Ю. Аншаковой «Гуманитарная деятельность Шведского Красного Креста в России во время голода начала 1920-х годов» [3], Т.И. Чековой «Помощь стран Северной Европы в борьбе с голодом 1921-1922 гг. на территории Самарской губернии» [4]. И, разумеется, нельзя не упомянуть фундаментальную работу профессора Полякова В.А. «Голод в Поволжье, 1919-1925 гг.: происхождение, особенности, последствия» [5].

В результате договора, заключенного между наркомом иностранных дел РСФСР Георгием Чичериным и руководителем делегации Международного Красного Креста Фритьофом Нансеном 27 августа 1921 года, был учрежден Международный комитет помощи России. Основными задачами Комитета были доставка и распределение гуманитарных грузов в голодающих местностях [6]. Одной из организаций, входивших в комитет, была организация Шведского Красного Креста.

Шведский Красный Крест имел самостоятельное финансирование, собственный аппарат и фактически с самого начала работы Комитета действовал независимо от его руководства. Районом деятельности Шведского Красного Креста была выбрана Самарская губерния.

Общее руководство Шведским Красным Крестом осуществлял родной брат короля Швеции принц Карл. Штаб-квартира ШКК находилась в Стокгольме по адресу: Артиллеригатан, 6. Принцем Карлом была определена стратегия организации деятельности ШКК в Самарской губернии и произведен набор кадров экспедиции, направляющейся для оказания непосредственной помощи на месте [7].

Ввиду недостаточно конкретных сведений об обстановке в голодающих местностях и ограниченного бюджета, первоначальная стратегия организации деятельности экспедиции ШКК заключалась во взятии под опеку небольшого района и полном его материальном и медицинском обеспечении. Продукты распределялись по следующему принципу: в селах с населением менее 500 человек продовольственные пайки выдавались в сухом виде на руки по заверенным спискам сельсоветов и волисполкомов через специальных представителей (два выборных на волость, по одному от совета и от голодающих). В волостных центрах и селах с большим количеством жителей открывались столовые с горячим питанием [8]. Кроме того, в волостных центрах открывались пекарни, продовольственные и вещевые склады, детприёмники, больницы.

В дальнейшем стратегия была признана руководством ШКК верной и не менялась на протяжении всей деятельности экспедиции ШКК в Самарской губернии. Район же деятельности постоянно увеличивался до августа 1922 года.

Управление экспедиции было организовано в соответствии с выбранной стратегией. Организационная структура экспедиции имела следующий вид:

1. Руководитель экспедиции. Осуществлял общее руководство и представительские функции на месте. Обладал полномочиями заключать договоры с советскими организациями и осуществлять набор русского персонала.

2. Первый заместитель руководителя. Дублировал функции руководителя и осуществлял общее руководство в период его отсутствия.

3. Заместитель руководителя - начальник складов. Осуществлял руководство работой центрального склада экспедиции в г. Самаре, вел учет приёмавыдачи грузов, распределял грузы по накладным с центрального склада по складам в районах деятельности экспедиции, имел право лично нанимать сторожей складов.

4. Заместитель руководителя по доставке грузов («транспортный контролер»). Имел четко выраженные логистические функции: составлял маршрутные расписания доставки грузов в Самару из портов Петрограда, Ревеля и Риги, назначал лиц, сопровождающих маршрутные поезда, имел полномочия ведения переговоров от лица ШКК с наркоматом путей сообщения, контролировал финансы, выделенные на доставку грузов, организовывал перевозку грузов внутри Самарской губернии, визировал накладные на выдачу грузов с центрального склада экспедиции.

5. Уполномоченные делегаты ШКК. Подчинялись руководителю экспедиции, в случае его отсутствия первому заместителю. Осуществляли общее руководство оказания помощи в районах деятельности ШКК. Район деятельности делегата ШКК обычно включал в себя одну-две расположенные по соседству волости. В круг непосредственных обязанностей входили: организация работы волостного склада ШКК, пекарни и стационарных столовых; набор русского персонала по представлению волисполкомов; содержание больницы, амбулаторий и детский приютов (с января 1922 года и детдомов); совместное с волисполкомом привлечение взрослого населения к общественным работам. Связь со штабом экспедиции осуществляли через посыльных и курьеров, с которыми также отправляли еженедельные отчеты и запросы на необходимые ресурсы. В случае необходимости делегаты обращались напрямую в местные органы ВЧК-ГПУ и милиции. Так, делегат капитан Муландер обратился в отделения милиции сел Воскресенки, Вязовый Гай и Колывани, в связи с 
ограблением неизвестными каравана со шведской гуманитарной помощью в районе ст. Кряж в ночь с 28 на 29 июня, и получил содействие в виде милицейского патруля и организации расследования происшествия [9].

6. Два доктора-эпидемиолога. Подчинялись руководителю экспедиции. Совершали еженедельные объезды районов деятельности ШКК, осуществляли прием больных, вакцинирование, амбулаторное лечение и в отдельных случаях хирургические операции.

7. Экономка-бухгалтер.

8. Делегат-курьер. Подчинялся руководителю экспедиции. Осуществлял оперативную связь и доставку корреспонденции и мелких грузов [6].

Важную роль в деятельности экспедиции играл инженер Юн Тунельд, представитель Шведского Красного Креста и глава шведской общины в Петрограде [10]. В тесном взаимодействии с полномочным представителем правительства РСФСР при всех иностранных организациях в Петрограде Зиноном Жуковым Юн Тунельд встречал в петроградском порту все пароходы с гуманитарными грузами для ШКК, организовывал погрузку этих грузов железнодорожные вагоны и составлял накладные для эшелонов, следовавших в Самару [11].

Второстепенной деятельностью экспедиции можно назвать распределение адресных посылок в Москве для шведских подданных. Распределение осуществлялось в стенах шведской торговой миссии в Москве под контролем ее главы Адольфа Лаурина. Всего было распределено 40 посылок [12].

Основная экспедиция отправилась из Швеции в октябре 1921 года. Уже 2 октября Фритьоф Нансен известил телеграммой из Женевы НКИД РСФСР о том, что поезд ШКК с продовольствием и медикаментами готов к отправлению, и попросил предоставить 20 товарных вагонов для доставки грузов из Петрограда в Самару [13]. В Самару экспедиция прибыла 6 декабря 1921 года в составе 9 человек: руководитель - Эрик Экстранд, первый заместитель Карл Делин, начальник складов - Карл Готлиб, «транспортный контролер» - Йёста Седергрен, доктор Вассен, делегаты Карин Линдскуг и Генри фон Крамер, экономка - Грета Сет, делегат-курьер - Гарри Густафсон. В январе к ним присоединятся Самюль Сарве, который сменит Седергрена (Седергрен отправится на Украину в Херсонский уезд организовывать работу по оказанию помощи шведской колонии Гаммал Свенскбю), делегат Свен Эдвард Норлин и доктор Скугсберг [7].

Первоначально экспедиция развернула работу в двух районах, включавших в себя Воскресенскую, Каменно-Бродскую, Вязово-Гайскую и ДубовоУметскую волости Самарского уезда. Жители этих сел ежедневно получали 8000 пайков с довольно высокой энергетической ценностью - 1300 калорий. Высокая калорийность пайков оставалась неизменной на протяжении всей деятельности ШКК [14].

Руководство Самарской губернии высоко оценило организацию работы ШКК. Так, председатель губисполкома Антонов-Овсеенко писал в статье «Истинно-культурная работа», опубликованной в газете «Коммуна»: «Уже на следующий день по своем прибытии экспедиция приступила к ознакомлению с районом, в котором ей предстояло развертывать ее работу».
Этот район недавно еще богатых сел - Воскресенская, Каменный Брод и т.д., в 16-40 верстах от Самары по тракту на Пугачев - застала она в отчаянном положении. Из 23.686 душ его населения лишь 4,6\% оказались способными держаться собственными средствами. За год число лошадей уменьшилось с 7872 до 1775, мелкий скот почти вовсе уничтожен.

Шведская экспедиция через несколько дней уже вела работу полным ходом. К середине января она выдавала ежедневно горячую пищу и хлеб 18800 чел., выдавала эту пищу на дом из общественных кухонь, устроенных в селениях - Воскресенском, Каменном Броде, Вязовом Гае, Колывани, Дергачи, Преображенке, Русских и в Мордовских Липягах» [15].

Столкнувшись с огромным числом голодающих и больных, случаями трупоедства, людоедства и другими ужасами, руководитель экспедиции Эрик Экстранд направил крайне эмоциональную телеграмму в Риксдаг с просьбой немедленно увеличить финансирование и штат экспедиции [16].

Получив увеличенное финансирование, ШКК развернул свою работу, на тех же принципах, в волостях: Воскресенской, Каменно-Бродской, ВязовоГайской, Дубово-Уметской, Титовской, Яблоневый Враг, Купинской, Сухая-Вязовка, Красно-Ярской, Черноречье [17]. К экспедиции присоединяются делегаты Дэвид Белин, Луиза Кириллина-Флак, капитан Муландер и Оскар Халлберг, которые возглавляют соответствующие округа [7].

Весной 1922 года для проведения посевной кампании ШКК выписал из Швеции 4 трактора. Для их обслуживания и обучения местных трактористов прибыл инженер-механик Бенгтссон. Механик напрямую подчинялся руководителю экспедиции. Наиболее способные местные трактористы были наняты ШКК и подчинены Бенгтссону. При направлении на работу в поле трактористы переходили в подчинение делегатам округов [18]. Кроме того, в Швеции были закуплены и привезены пароходом «Калевипоэг» 800 тонн семян ржи и 500 тонн фуража для рабочего скота [19].

Такой принцип организации управления оставался у ШКК неизменным на протяжении всего периода деятельности в Самарской губернии. В зависимости от стоявших задач менялось только количество делегатов.

Оценивая организационную структуру и систему управления экспедиции ШКК, можно сделать следующие выводы. Организационная структура экспедиции представляла собой предельно дебюрократизированную систему, наделявшую отдельных исполнителей довольно широкими полномочиями в пределах исполнения своих обязанностей. Исполнители в своих округах были достаточно самостоятельны для принятия оперативных решений в меняющейся обстановке. Управление было нацелено на решение конкретных проблем, предоставляло инициативу исполнителям и основную свою роль видело в распределении ресурсов, реагировании на сигналы с мест Кроме того, руководство управления активно выстраивало взаимоотношения с местными властями, что позволяло также снизить количество бюрократических проблем и пользоваться поддержкой советских органов. 


\section{Список литературы:}

1. Голод в Средневолжском Крае в 20-30-е годы XX века. Т. 1. Голод в Самарской губернии в 20-е годы XX века: сборник документов ГБУСО «Самарский областной государственный архив социальнополитической истории», ГБУСО «Центральный государственный архив Самарской области». Самара, 2014. 513 c.

2. На фронте голода. Издание Самарской губернской комиссии помощи голодающим. Самара, 1922. $121 \mathrm{c}$.

3. Аншакова Ю.Ю. Гуманитарная деятельность Шведского Красного Креста в России во время голода начала 1920-х годов // Российская государственность: от истоков до современности: материалы междунар. науч. конф. Самара, 13-15 сентября 2012 г. Самара: Издательство Самарского научного центра PAH, 2012. C. 448-453.

4. Чекова Т.И. Помощь стран Северной Европы в борьбе с голодом 1921-1922 гг. на территории Самарской губернии // Краеведческие записки. Выпуск IX. Самара, 2000. C. 47-54.

5. Поляков В.А. Голод в Поволжье, 1919-1925 гг.: происхождение, особенности, последствия. Волгоград, 2007. Гл. 2. 735 с.

6. Бюллетень ЦК Помгол ВЦИК. М., 1921. № 1. C. 39-44.

\section{ORGANIZATIONAL STRUCTURE OF THE SWEDISH RED CROSS MISSION TO ASSIST THE STARVING SAMARA PROVINCE DURING THE FAMINE OF 1921-1923} (C) 2018
7. Национальный архив Швеции. Riksarkivet. SKR/Byrån för hjälpverksamhet i Ryssland/F/Vol. 1 .

8. Деятельность Самарской губернской комиссии помощи голодающим по отчетам (за декабрь 1921 г.

9. Центральный государственный архив Самарской области. Ф. Р. 79. Ф. 1. Д. 24, лл. 316-317.

10. Бенгт Янгфельдт. От варягов до Нобеля. Шведы на берегах Невы. М.: Издательство «Ломоносовъ», 210. 399 c.

11. Riksarkivet. SKR/Byrån för hjälpverksamhet i Ryssland/F/Vol. 6.

12. Государственный архив Российской Федерации (ГАРФ). Ф. 1058. Оп. 1. Д. 333. Л. 43.

13. О деятельности Ф. Нансена по оказанию помощи голодающим в России (1921-1922 гг.) // Исторический архив, 1962. № 3. С. 66.

14. ГАРФ. Ф. 1058. Оп. 1. Д. 688. Л. 14-16.

15. Антонов-Овсеенко «Истинно-культурная работа», Коммуна, 1922, 04 февраля. 1 с.

16. Folkets Dagblad Politiken, 1922, 23 января. 2 c.

17. Бюллетень ЦК Помгол ВЦИК. 1922. № 5-6-7.

C. 15 .

18. Riksarkivet. SKR/Byrån för hjälpverksamhet i Ryssland/F/Vol. 2.

19. Отчет о деятельности Шведского Красного Креста в России // ГАРФ. Ф. 1064. Оп. 6. Д. 88. Л. 14. - июнь 1922 г.). Самара, 1922. С. 78-79.

\author{
Tsidenkov Grigory Gennadievich, candidate of sociological sciences, \\ associate professor of Management and Service Department \\ Samara State University of Social Sciences and Education (Samara, Russian Federation)
}

\begin{abstract}
In the period from December 1921 to August 1923 in the Samara Region, the expedition of the Swedish Red Cross carried out humanitarian activities. The paper presents the personnel structure and the principles of the expedition management. The paper also presents the staff and the principles for the expedition management. The staff of the expedition are personified with their positions and responsibilities. The author specifies the reasons for the growing increase in the expedition staff The basic data presented in the paper is a result of a three-month research at the National Archives of Sweden (Riksarkivet). The paper presents the point of view of the Soviet authorities on the effectiveness of the work of the Swedish Cross. All the main administrative districts of the Samara province, where the Swedish Red Cross delegates worked, are specified. The materials, presented in the paper, expand our understanding of the activities of foreign humanitarian missions in the Volga Region in 1921-1923 and can be used to analyze the effectiveness of the expedition of the Swedish Red Cross in the Samara province in this period.

Keywords: famine of 1921-1923; foreign aid; Swedish Red Cross; International Committee for Russian Relief; Swedish Red Cross expedition; Samara province; management; organizational structure; food distribution; Industrial assistance.
\end{abstract}

УДК 908(470)

Статья поступила в редакцию 23.09.2017

\title{
КОНОКРАДСТВО В САМАРСКОЙ ГУБЕРНИИ В 1923-1925 ГОДАХ
}

(C) 2018

Гизатулин Шамиль Тахирович, кандидат исторических наук

Главное управление Министерства внутренних дел Российской Федерации по Самарской области (2. Самара, Российская Федераиия)

Аннотащия. В данной статье рассматривается проблема конокрадства в Самарской губернии в 19231925 гг. Проведено изучение причин, динамики краж лошадей в регионе, а также мер борьбы органов правопорядка с данным криминальным явлением. В работе указаны факторы, способствовавшие, наряду с общими неблагоприятными социально-экономическими условиями начала 1920-х годов, росту данного вида преступности в регионе. На основе статистических показателей милиции и уголовного розыска изучены способы краж лошадей в губернии, причины роста данного вида преступности в 1923 г. и снижения к концу 1925 г. Рассмотрены проблемы профессионального конокрадства и этнической преступности (криминальная актив- 